\title{
Pemberdayaan Posbindu Untuk Meningkatkan Derajat Kesehatan Masyarakat Di Banguntapan
}

\author{
Fardhiasih Dwi Astuti*, Rokhmayanti, Siti Kurnia Widi Hastuti \\ Universitas Ahmad Dahlan \\ Email: *fardhiasih.dwiastuti@ikm.uad.ac.id,rokhmayanti@ikm.uad.ac.id, \\ kurnia.widihastuti@ikm.uad.ac.id
}

Diterima: Februari 2021 | Dipublikasikan: Juni 2021

\begin{abstract}
ABSTRAK
Penyakit tidak menular (PTM) merupakan penyebab utama kematian di dunia. 70\%. kematian tiap tahun disebabkan PTM. Tingginya kematian yang disebabkan PTM, perlu dilakukan deteksi dini dan pengobatan yang tepat. Hasil survey masyarakat Plumbon diketahui Riwayat peyakit terbanyak adalah kadar kolesterol tinggi $42 \%$, hipertensi $19 \%$, dan diabetes militus $9,5 \%$. Deteksi dini di masyarakat dapat dilakukan di posbindu. Kegiatan posbindu merupakan kegiatan promotif dan preventif yang melibatkan masyarakat. Prencanaan, pelaksanaan dan pemantauan serta penilaian dilakukan dari dan oleh masyarakat. Kegiatan tersebut diperlukan keterampilan kader kesehatan dalam menagani posbindu. Berdasarkan hal tersebut perlu adanya pemberdayaan kader di posbindu untuk meningkatkan derajat kesehatan masyarakat. Metode yang digunakan dalam pengabdian ini adalah penyuluhan dan pelatihan pada kader kesehatan untuk meningkatkan pengetahuan dan keterampilan kader dalam melakukan kegiatan posbindu. Keterampilan kader diharapkan dapat mendeteksi faktor risiko masyarakat agar dapat dilakukan pencegahan sedini mungkin. Kegiatan dilaksanakan pada tanggal 19-20 November 2020, diikuti oleh 15 kader kesehatan di Padukuhan Plumbon Banguntapan Bantul. Hasil kegiatan diketahui terjadi peningkatan pengetahuan kader tentang posbindu dan keterampilan kader dalam melakukan pemeriksaan berat badan,tinggi badan, mengukur lingkar perut, tekanan darah, pemeriksaan darah gula,kolesterol dan asam urat. Kegiatan posbindu yang dilakukan dapat digunakan sebagai deteksi dini penyakit tidak menular.
\end{abstract}

Kata Kunci: Posbindu, Pelatihan, Penyakit tidak menular

\section{ABSTRACT}

Non-communicable diseases (PTM) are the leading cause of death in the world. $70 \%$ of deaths each year are caused by PTM. The high number of deaths caused by PTM requires early detection and appropriate treatment. The Plumbon community survey results showed that most disease histories were high cholesterol levels 42\%, hypertension 19\%, and diabetes mellitus 9.5\%. Screening non-communicable diseases for Early detection in the community can be done at Posbindu. Posbindu activities are promotive and preventive activities that involve the community. Planning, implementation, and monitoring and assessment are carried out from and by the community. These activities require the skills of health cadres in handling Posbindu. Based on this, it is necessary to empower cadres in Posbindu to improve community health status. The method used in this service is counseling and training for health cadres to increase cadres' knowledge and skills in carrying out Posbindu activities. Risk factors and preventing noncommunicable disease can be to do by Cadres. Ahmad Dahlan Team was held the training on 19-20 November 2020, attended by 15 health cadres at Padukuhan Plumbon Banguntapan Bantul. The activity results showed an increase in cadres 'knowledge of Posbindu and cadres' skills in checking body weight, height, measuring stomach circumference, blood pressure, containing blood sugar, cholesterol, and uric acid. Posbindu activities carried out can be used as early detection of non-communicable diseases.

Keywords: Posbindu, Training, Non-communicable disease.

\section{PENDAHULUAN}

Penyakit tidak menular (PTM) merupakan penyebab utama kematian di dunia. $70 \%$. kematian tiap tahun disebabkan PTM. Pervalensi penyakit tidak menular di Indonesia dari tahun 2007 - 2018 mengalami peningkatan seperti diabetes, hipertensi, stroke, penyakit sendi/rematik (Kemenkes RI, 2020). Hipertensi $(57,6 \%)$, artritis $(51,9 \%)$,stroke $(46,1 \%)$, masalah gigi dan 
mulut $(19,1 \%)$, penyakit paru obstruktif menahun $(8,6 \%)$ dan diabetes mellitus $(4,8 \%)$ merupakan penyakit yang banyak diderita lansia (Kemenkes, 2018).

Berdasarkan hasil riset kesehatan 2018, prevalensi penduduk dengan tekanan darah tinggi sebesar $34,11 \%$. Dengan bertambahnya umur prevalensinya semakin meningkat. Prevalensi obesitas IMT $\geq 25$ sbesar $35,4 \%$ dan yang $\geq 27$ sebesar $21,8 \%$. Hal ini meningkatkan resiko terjadinya penyakit tidak menular. (Kemenkes RI, 2020)

Di kabupaten Bantul, penyakit hipertensi merupakan penyakit yang tertinggi berdasarkan kunjungan rawat jalan dan rawat inap (Dinkes Kab Bantul, 2020). Data hasil survey secara langsung di masyarakat Plumbon Desa Banguntapan menujukan terdapat 106 masyarakat yang disurvey dan $21(19,8 \%)$ orang mempunyai riwayat penyakit. Riwayat peyakit terbanyak adalah kadar kolesterol tinggi 42\%, hipertensi $19 \%$, dan diabetes militus $9,5 \%$.

Kondisi status gizi di masyarakat Plumbon dari 106 responden didapatkan 44,3\% mengalami kegemukan dan $42 \%$ tidak melakukan aktifitas fisik. Prilaku merokok pada masyarakat didapatkan data sebesar $11 \%$. Hal ini dapat meningkatkan resiko masyarakat terhadap penyakit tidak menular. Pengetahuan masyarakat terkait Pos Pembinaan terpadu (Posbindu) sangat mempengaruhi partisipasi masyarakat dalam kegiatan Posbindu. Kegiatan ini sangat bermanfaat bagi pencegahan penyakit tidak menular seperti hipertensi, diabetes dan lain lain (Fuadah \& Rahayu, 2018).

Pencegahan terjadinya penyakit tidak menular dapat dilakukan dengan pemeriksaan kesehatan (Medical Check-Up) hal ini dapat mendeteksi sedini mungkin penyakit. Mendeteksi penyakit yang mungkin timbul merupakan hal yang sangat penting, karena tidak semua penyakit mempunyai gejala yang jelas, terkadang kita baru mengetahui penyakit tersebut saat melakukan pemeriksaan kesehatan (Kemenkes RI, 2016) Kegiatan Posbindu merupakan kegiatan promotif dan preventif yang melibatkan masyarakat. Prencanaan, pelaksanaan dan pemantauan serta penilaian dilakukan dari dan oleh masyarakat (Kemenkes RI, 2019). Deteksi dini di masyarakat dapat dilakukan di posbindu. Dengan menilai risiko seseorang dengan kuesioner terhadap penyakit tidak menular (Kemenkes RI, 2020). Pendeteksian faktor risiko selanjutnya dipastikan dengan pemeriksaan darah dengan alat yang sederhana untuk memastikan diagnosis. Kegiatan tersebut diperlukan keterampilan kader kesehatan dalam menagani Posbindu. Berdasarkan hal tersebut perlu adanya pemberdayaan kader di Posbindu untuk meningkatkan derajat kesehatan masyarakat.

\section{Solusi permasalahan}

Permasalahan yang ada di desa tersebut dapat diatasi dengan adanya program kemitaraan yang dapat mengurangi dan mencegah penyakit tidak menular dan meningkatkan pola hidup sehat di masyarakat. Program yang ditawarkan sebagai solusi yang tepat berdasarkan prioritas masalah.

Solusi yang ditawarkan untuk permasalahan tersebut yaitu :

1. Peningkatan pengetahuan masyarakat tentang penyakit tidak menular.

2. Peningkatan pengetahuan tentang pencegahan penyakit tidak menular.

3. Pelatihan kader dalam melaksanakan kegiatan posbindu yang dilakukan kader kesehatan.

4. Meningkatkan ketertiban administrasi pada Posbindu di Plumbon, Banguntapan Bantul.

Solusi yang dilakukan dan luaran yang ditargetkan untuk permasalahan tersebut diharapkan dapat meningkatkan pengetahuan masyarakat tentang penyakit tidak menular. Selain itu juga masyarakat dapat melakukan pola hidup sehat sebagai pencegahan penyakit tidak menular.

Tujuan pengabdian ini meliputi :

1. Meningkatkan pengetahuan kader tentang faktor risiko penyakit tidak menular

2. Meningkatkan pengetahuan kader tentang pencegahan penyakit tidak menular

3. Meningkatkan keterampilan kader dalam pengukuran faktor risiko yang dilakukan di Posbindu.

4. Meningkatkan keterampilan kader tentang administrasi pada Posbindu. 


\section{METODE PEIAKSANAAN}

\section{Metode Pelaksanaan :}

Metode yang dilakukan dapam pengabdian ini meliputi:

Tahap 1: pra pelaksanaan.

Pengusung mengajukan kerjasama dengan dusun Plumbon, Desa Banguntapan Bantul. Melalui kerjasama dengan mitra, terdapat manfaat yang saling menguntungkan dan kerjasama dalam penyelenggaraan kegiatan.

Tahap 2: Pelaksanaan

Pelaksanaan kegiatan dilakukan dengan memberikan ceramah tentang faktor risiko penyakit tidakmenular dan pencegahannya, dilanjutkan dengan praktik pelaksanaan posbindu. Kegiatan praktik dilakukan meliputi pengukuran tinggi badan, berat badan, penilaian Index masa tubuh dan suhu. Pengukuran tekanan darah, pengukuran kadar gula darah, kolesterol dan asam urat. Penilaian faktor risiko penyakit tidak menular dan pencatatannya.

Tahap 3: Monitoring dan evaluasi

Monitoring dan evaluasi dilakukan dengan menindaklanjuti kegiatan posbindu yang dilaksanakan di dusun Plumbon dan pendampingan pada kader dalam melaksanakan posbindu.

\section{HASIL KEGIATAN}

Kegiatan pemberdayaan ini dilaksanakan tanggal 19 - 20 November 2020 secara langsung dengan tatap muka, ceramah dan praktik secara langsung. Dengan kondisi adaya wabah, maka peserta yang terlibat dalam kegiatan hanya terbatas kader posbindu dengan jumlah 15 orang.

Karakteristik peserta dalam kegiatan dapat dilihat pada Tabel 1:

Tabel 1: Karakteristik Kader Posbindu Dukuh Plumbon Banguntapan Bantul

\begin{tabular}{cccc}
\hline No & Keterangan & jumlah & \% \\
\hline $\mathbf{1}$ & Jenis kelamin & & 100 \\
& Perempuan & 15 & \\
& Laki laki & - & 40 \\
\hline $\mathbf{2}$ & Umur & & 60 \\
& $30-50$ & 6 & 53,3 \\
& $51-70$ & 9 & 13,3 \\
$\mathbf{3}$ & Tingkat pendidikan & & 33,3 \\
& SMA & 8 & 26,7 \\
& D3 & 2 & 26,7 \\
& S1 & 5 & 26,7 \\
& Lama menjadi kader & & 20 \\
\hline
\end{tabular}

Kader kesehatan yang mengikuti pelatihan semua berjenis kelamin perempuan. Sebagian besar sudah berumur lebih dari 50 tahun $(60 \%)$. Berdasarkan tingkat pendidikan semua kader berpendidikan minimal SMA (Sekolah Menengah Atas). Lama menjadi kader ada yang kurang dari 1 tahun, ada yang sudah lebih dari 15 tahun. Namun demikian kegiatan pelatihan pada kader kesehatan ini belum pernah dilakukan di wilayah tersebut. Terdapat kader yang dilatih di tempat lain, namun kader yang dilatih hanya sedikit dan kegiatan pelatihan kader yang dilakukan ini dapat mencakup sebagian besar kader di dusun Plumbon.

Kegiatan dilakukan dengan memberikan informasi terkait faktor risiko penyakit tidak menular dan pencegahannya. Peran kader kesehatan yang sangat penting dalam pencegahan penyakit tidak menular. Kegiatan Posbindu yang dilakukan secara teratur dapat dimanfaatkan 
sebagai pengontrolan kondisi kesehatan masyarakat, dan sebagai deteksi dini penyakit tidak menular seperti diabetes militus dan hipertensi.

Pelatihan pelaksanaan Posbindu yang dilakukan secara langsung dengan praktik pengukuran berat badan, Tinggi badan, Index masa tubuh, suhu tubuh, tekanan darah, dan pemeriksaan darah kadar kolesterol, gula dan asam urat. Kader kesehatan yang dilatih sangat antusias dalam mengikuti pelatihan dan dapat langsung mencoba melakukan sendiri. Dengan pelatihan ini kader kesehatan dapat menyimpulkan kondisi kesehatan yang diperiksa dan dapat memberikan saran sebagai pencegahan penyakit tidak menular. Jika terdapat warga yang mengalami gangguan kesehatan maka kader dapat merujuk ke Puskesmas.

Pelatihan ini menjadi bekal kader kesehatan dalam melakukan kegiatan Posbindu. Pemberian alat perlengkapan Posbindu dapat dimanfaatkan untuk keberlanjutan kegiatan Posbindu dengan memperhatikan protokol kesehatan. Pada kegiatan pengabdian ini tim penggusung kegiatan selalu mengingatkan untuk tetap mematuhi protokol kesehatan guna pencegahan penularan Covid 19.

Berdasarkan hasil pengukuran pengetahuan Posbindu pada kader kesehatan diketahui sebelum pelaksanaan pelatihan didapatkan nilai terendah dari responden 12 pertanyaa benar atau $60 \%$. Dan sesudah pelatihan nilai terendah responden sebesar 16 atau $80 \%$ benar. Berdasarkan rata rata terjadi peningkatan sebelum 14,86 menjadi 17,87 seperti pada Tabel 2 berikut ini:

Tabel 2 : Hasil Pengukuran Pengetahuan kader kesehatan tentang Posbindu.

\begin{tabular}{rcccc}
\hline & Minimal & Maksimal & Rata rata & $\begin{array}{c}\text { Standar } \\
\text { deviasi(SD) }\end{array}$ \\
\hline Sebelum peatihan & $12(60 \%)$ & $18(90 \%)$ & 14,86 & 1,92 \\
Sesudah Pelatihan & $16(80 \%)$ & $19(95 \%)$ & 17,87 & 1,18 \\
\hline
\end{tabular}

Berdasarkan hasil pengukuran pengetahuan kader kesehatan tentang Posbindu dapat dilihat terjadi peningkatan rata rata pengetahuan dari sebelum dilakukan pelatihan dibanding dengan sesudah dilakukan pelatihan.

Berikut ini gambar kegiatan yang dilaksanakan.

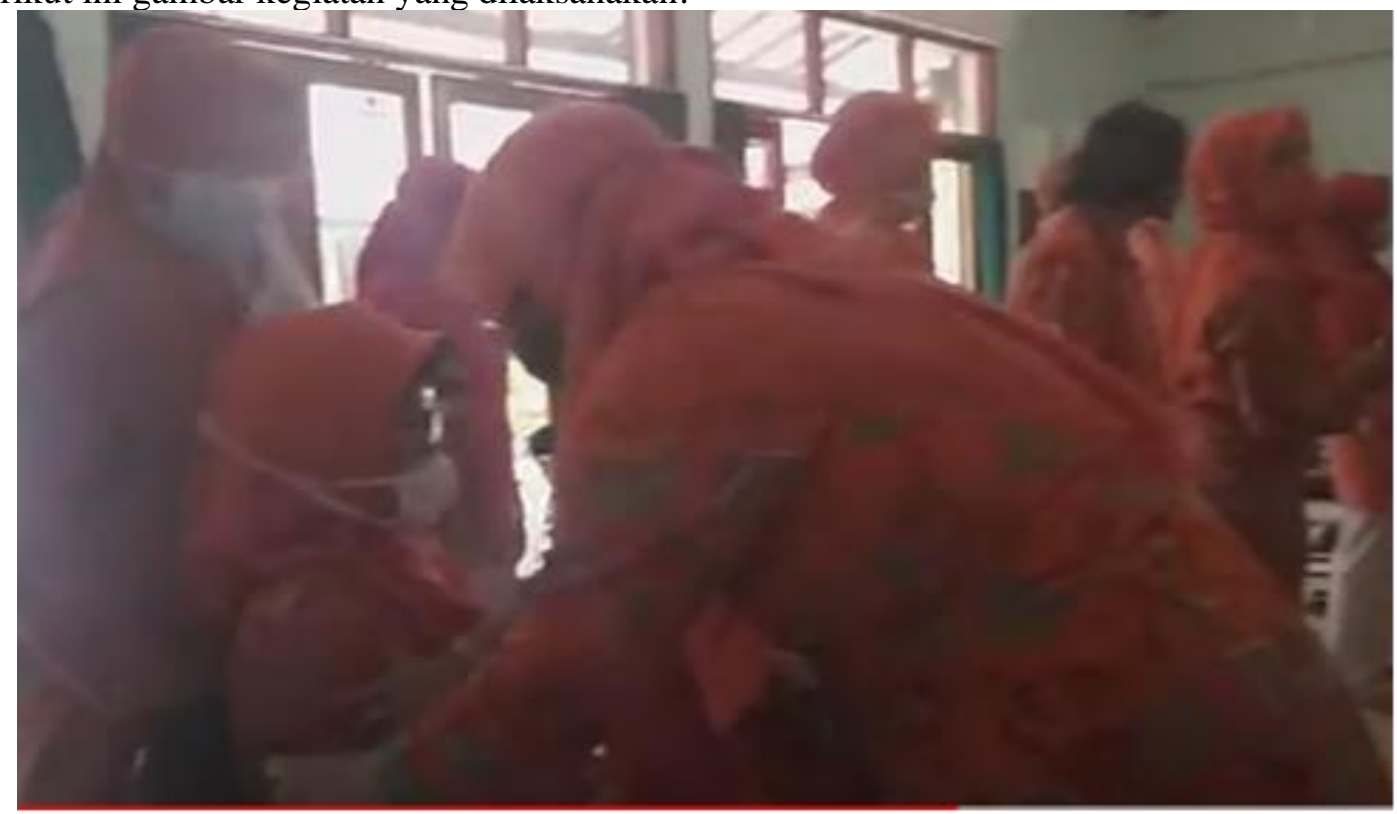

Gambar 1: Praktik pengukuran tekanan darah. 


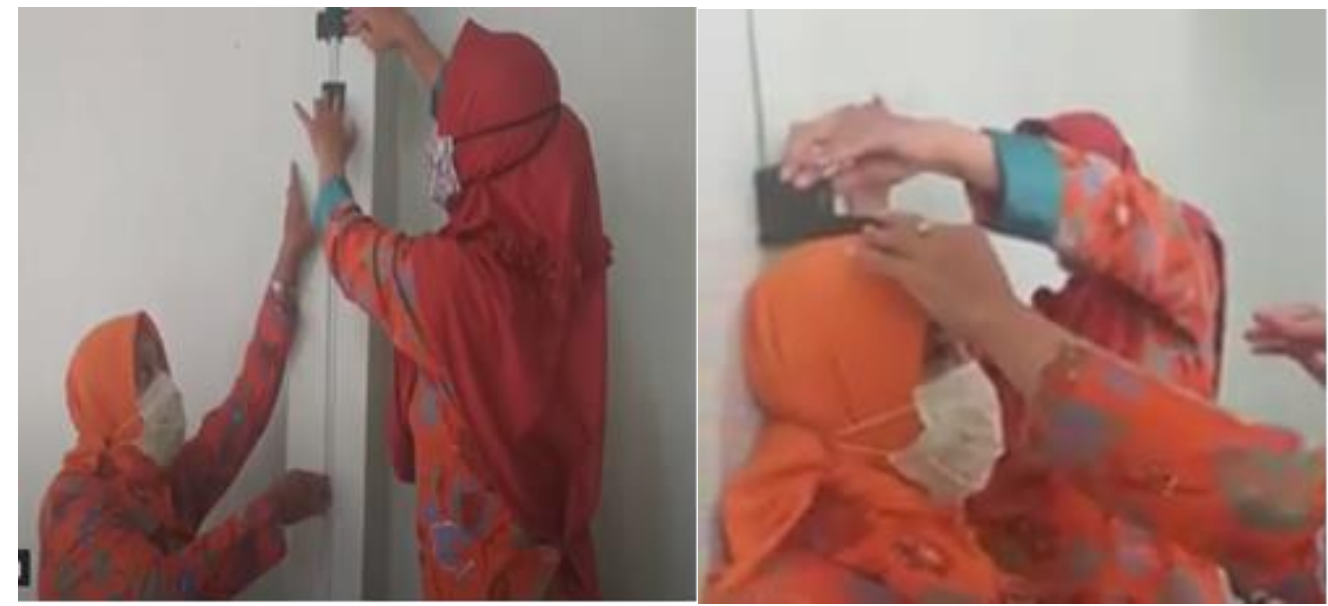

Gambar 2: Praktik pemasangan dan pengukuran tinggi badan.

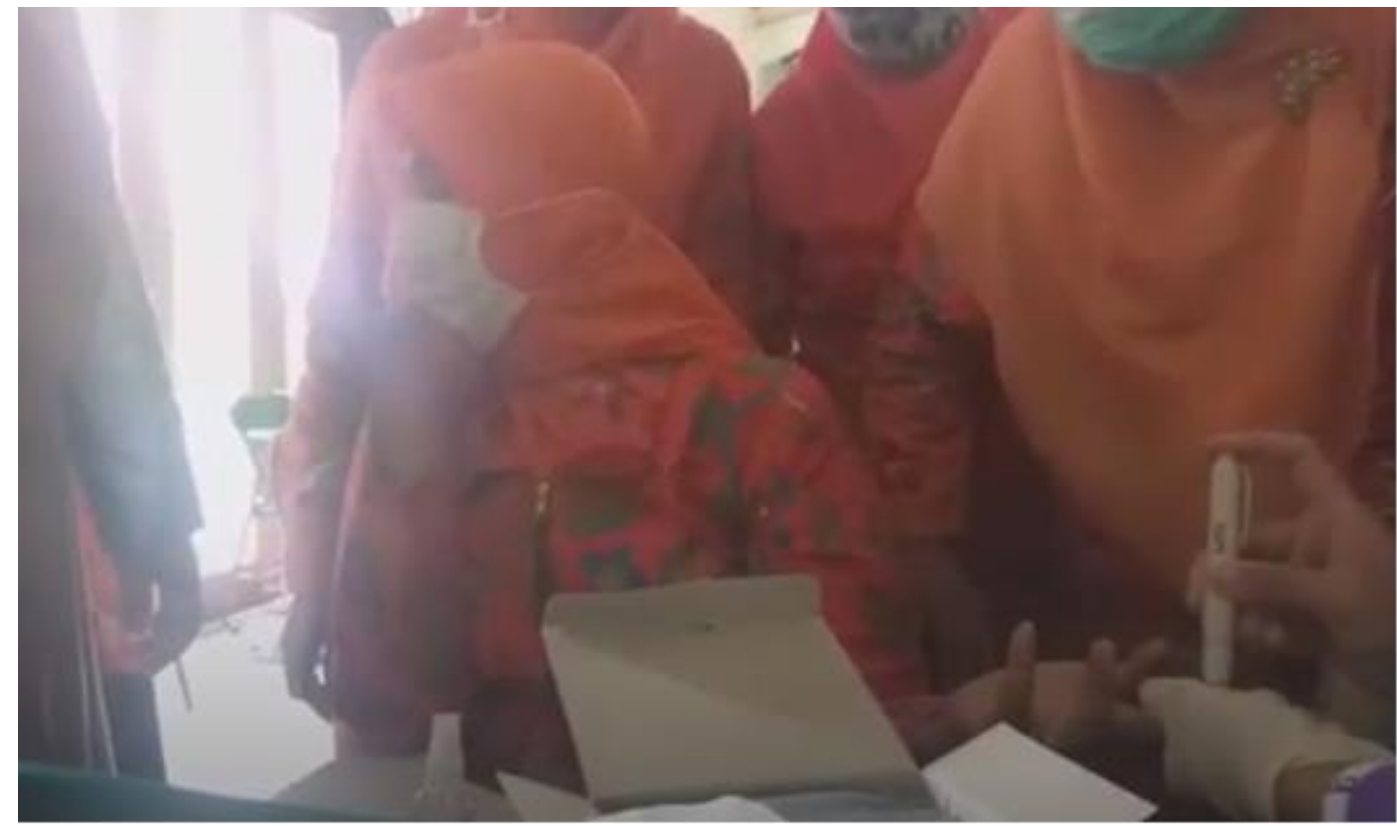

Gambar 3: Praktik Pemeriksaan Kadar Gula darah

Berdasarkan hasil pelaksanaan diketahui tingkat pendidikan kader sebagian besar SMA dan sarjana. Pada kondisi ini potensi yang dimiliki kader cukup bagus, ditunjukkan dari hasil jawaban sebelum dilakukanya pelatihan, pengetahuan kader dengan nilai terendah 60\% menjawab dengan benar. Sesudah pelatihan diketahui terjadi peningkatan nilai rata rata pengetahuan responden dengan nilai terendah responden sebesar $80 \%$ menjawab dengan benar. Berdasarkan nilai rata rata juga terjadi peningkatan. Pengetahuan kader kesehatan tentang Posbindu berhubungan dengan tingkat pendidikan responden. Hal ini sesuai dengan penelitian sebelumnya yang menunjukkan adanya hubungan pendidikan dengan pengetahuan. Pada orang yang berpendidikan lebih tinggi memudahkan mereka dalam memahami suatu hal (Fuadah \& Rahayu, 2018)

Kegiatan pelatihan sangat dibutuhkan oleh kader, dengan pelatihan kader mempunyai kemampuan dalam promosi kesehatan dan dalam pelaksanaan Posbindu. Kader yang terlatih menunjukkan kinerja yang lebih baik (Hastuti et al., 2019).

Kader juga mempunyai peran sebagai motifator masyarakat untuk berperanserta dalam kegiatan posbindu dengan pengetahuan kader yang baik dapat meningkatkan partisipasi masyarakat dalam kegiatan posbindu (Hastuti et al., 2019). Hal ini akan berdampak pada banyaknya masyarakat yang terscreening penyakit tidak menular. Hasil screening pada lansia di 
Banyumas menujukkan terdapat $47,8 \%$ lansia berisiko terjadinya hipertensi (Suparti \& Handayani, 2019). Kegiatan screening dapat dilakukan di Posbindu. Dengan adanya kegiatan screening tersebut, masyarakat yang mengalami gangguan kesehatan akan terdeteksi secara dini sehingga mendapatkan penanganan secara cepat.

Berdasarkan hasil analisis beberapa penelitian sebelumnya, kader berperan dalam pencegahan adanya komplikasi pada hipertensi. Peran ini sangat penting dengan melakukan pendampingan pada penderita hipertensi dalam mengelola gaya hidup masyarakat dengan meningkatkan aktifitas fisik, mengurangi konsumsi garan dan prilaku hidup bersih dan sehat (Istifada \& Rekawati, 2019).

Kegiatan pelatihan ini sangat bermanfaat dalam meningkatkan keterampilan kader dalam melakukan praktik pengukuran berat badan,tinggi badan, tekanan darah dan pemeriksaan darah. Hal ini sesuai dengan hasil penelitian yang menunjukkan pelatihan kader yang berulang ulang akan meningkatkan keteranpilan kader (Lusiyana, 2020). Kegiatan pelatihan ini perlu adanya tindaklanjut untuk monitoring pelaksanaan kegiatan Posbindu yang dilaksanakan dan pendampingan dalam pemeriksaan agar keteranpilan kader lebih baik.

\section{KESIMPULAN DAN SARAN}

Berdasarkan hasil kegiatan pengabdian yang dilakukan dapat disimpulkan

1. Kegiatan pelatihan kader kesehatan dapat meningkatkan pengetahuan kader tentan posbindu.

2. Dengan pelatihan yang dilaksanakan keterampilan kader terjadi peningkatan dalam melakukan pemeriksaan berat badan, tinggi badan, tekanan darah dan pemeriksaan kadar gula darah.

3. Kegiatan Posbindu dapat bermanfaat dalam deteksi dini penyakit tidak menular.

Saran untuk kegiatan selajutnnya adalah pendampingan yang berkelanjutan pada kader dan Posbindu di wilayah lain agar masyarakat dapat mempunyai derajat kesehatan yang leih baik.

\section{UCAPAN TERIMA KASIH}

Ucapan terima kasih kami sampaikan kepada lembaga penelitian dan pengabdian masyarakat Universitas Ahmad Dahlan yang telah memberikan dana atas terselengaranya kegiatan pengabdian ini. Terimakasih juga kami sampaikan kepada kepala Dukuh Plumbon dan Puskesmas Banguntapan 3 Bantul yang telah memberikan dukungan terhadap kegiatan ini, serta partisipan kader dan mahasiswa yang telah membantu jalannya kegiatan.

\section{DAFTAR PUSTAKA}

Dinkes Kab Bantul. (2020). Profil Kesehatan Kabupaten Bantul 2020. Dinas Kesehatan Kab. Bantul.

Fuadah, D. Z., \& Rahayu, N. F. (2018). Pemanfaatan Pos Pembinaan Terpadu ( Posbindu ) Penyakit Tidak Menular ( PTM ) Pada Penderita Hipertensi ( Utilization Of Integrated Posted Cooperation ( Posbindu ) of Non-Communicable Disease of Patients with Hypertension ). Jurnal Ners Dan Kebidanan, 5(1), 20-28. https://doi.org/10.26699/jnk.v5i1.ART.p020

Hastuti, N. M., Pupitasari, R., \& Sugiarsi, S. (2019). Peran Kader Kesehatan Dalam Program Posbindu Penyakit. MATERNAL, III(2), 57-61.

Istifada, R., \& Rekawati, E. (2019). Peran Kader Kesehatan Dalam Promosi Pencegahan Komplikasi Hipertensi Di Wilayah Perkotaan : Literatur Review. Dunia Keperawatan, 7(1), $28-40$. 
Kemenkes, R. (2018). Profil Kesehatan Indonesia 2017. http://www.depkes.go.id/resources/download/pusdatin/profil-kesehatan-indonesia/Datadan-Informasi_Profil-Kesehatan-Indonesia-2018.pdf

Kemenkes RI. (2016). Elderly Condition in Indonesia. In Report. https://pusdatin.kemkes.go.id/folder/view/01/structure-publikasi-pusdatin-info-datin.html, diakses tanggal 12 Oktober 2020

Kemenkes RI. (2019). Petunjuk Teknis Pos Pembinaan Terpadu Posbindu bagi Kader. Direktorat jendral Pencegahan dan Pengendalian Penyakit.

Kemenkes RI. (2020). Profil Kesehatan Indonesia Tahun 2019. https://pusdatin.kemkes.go.id/resources/download/pusdatin/profil-kesehatanindonesia/Profil-Kesehatan-indonesia-2019.pdf diakses tanggal 12 Oktober 2020

Lusiyana, N. (2020). Optimalisasi peran kader posbindu dalam deteksi hipertensi di posbindu kedungpoh tengah wonosari yogyakarta. Jurnal Education and Development, 8(2), 167170.

Suparti, S., \& Handayani, D. Y. (2019). Screening Hipertensi pada Lansia Di Wilayah Puskesmas Banyumas. Indonesian Journal for Health Sciences, 2(2), 84. https://doi.org/10.24269/ijhs.v2i2.875 